ligaments may be advantageously stretched by more potent means, which nearly two years ago I began tentatively, and which I lnave employed in its present perfected form for more than a year.

Of course, a simple lumbar curve is the most easily dealt with, and I will begin with the procedure as adapted to that sort of deformity, only premising that these methods are not used to the exclusion, but come in aid, of the various devices described in my former writings.

The case about to be considered (illustrated by Fig. 1) is one of rather severe lumbar curvature to the left, without, or with only slight secondary dorsal curve-a ca:e in which shortening of muscles and ligaments is diagnosed. In order to stretch these, I use a girth of strong webbing three inches wide and two feet and a half long, each end of which is sewn round a strons flax cord of rather greater lenoth, so that the whole forms a sling about four and a half feet long when folded in two. The webbing part of this is placed on the left side of the patient's loins (a pad protecting the soft parts may be improvised from a folded tlannel petticoat or may be more artistically made), and the cord is hitched upon a hook secured to the wall at about the height of this part of the figure. 'The patient must stand so that this girth is tight against her loin, but to obviate compression of the abdomen wooden strut from one to one and a half foot long is placed between the two ends of the webbing which project on the patient's right. ${ }^{3}$ Thus arranged, the patient throws the upper part of her body sharply and powerfully

FIG. 2.

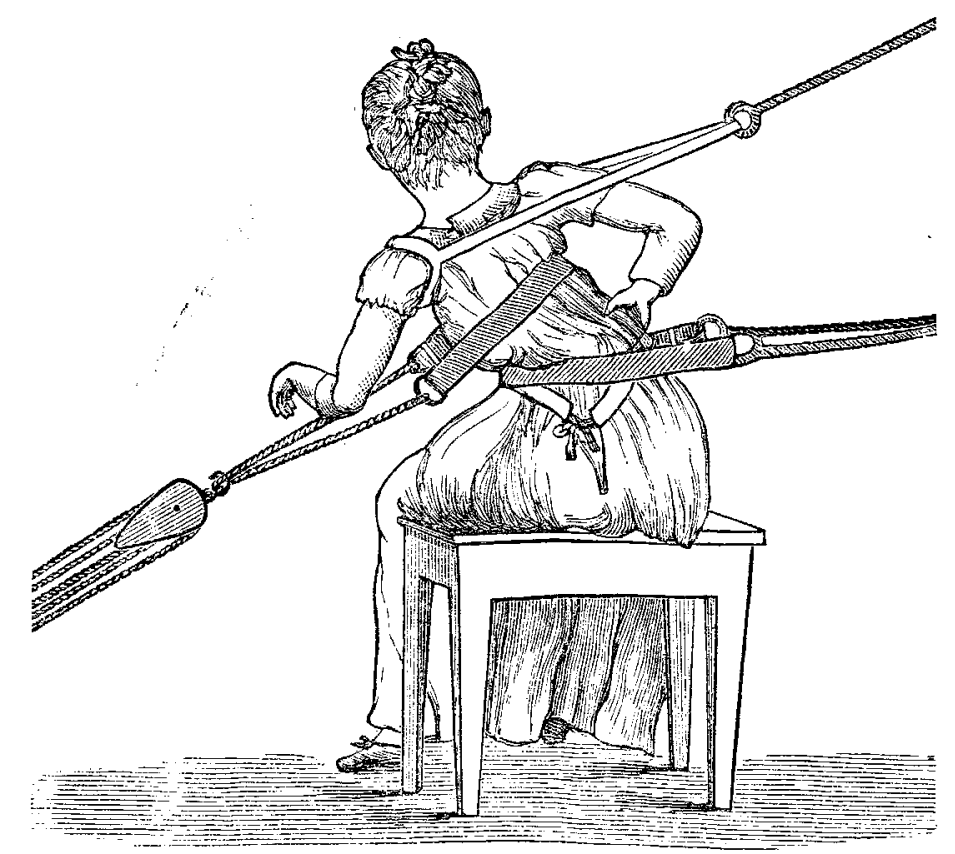

to the left. She is to repeat this on each occasion severa times, and the occasions are to recur twice or even thrice a day, according to power and health. These procedures suffice for the not very severe cases, and in more strongly marked ones, when the following more potent means are used, they should be additionally practised. The more potent means are that the surgeon uses force to bend his patient's body. He may stand on her left, and, passing one arm behind the other in front of her, clasp his hands just under her right axilla and drag her, forcibly, even by considerable jerks, over to the left; or he may let her sit on a chair, and, placing lis knee on the right side of the seat to prevent the pelvis slipping, may, with his hand on the right side of the chest, force her over to the left. In still worse cases, pulleys may be used some what after the manner now to be described for dorsal curve.

When dealing with an S-shaped curve in its more advanced stages the arrangements are not quite so simple, and Fig. 2 requires some explanation. It shows a patient sitting, which is the most desirable posture. The loin girth being arranged as above described, another similar loop is for the present allowed to hang loosely about her waist. She is then directed to bend over towards the left; a padded loop with webbing straps is passed over her lett arm up to the axilla, and the cord attached thereto, which runs through a pulley, is drawn rather tight, and secured on a blind-cord

3 This and the pad are omitted in the figure. catch. The middle girth, till now hanging loose, is placed on her right side, opposite the most aberrant part of the dorsal spine; and into the rope part of the loop is hitched the hook of a system of pulleys such as is used for reducing dislocation after the Astley-Cooper method; the hook on the other set is caught in a cellar-flap-ring screwed to the floor about eight feet from the patient. The surgeon sees that the patient does not sit perfectly square between the hooks and the cellar flap ring, but so turned that slie faces a little (forty-five degrees) towards the latter; ${ }^{4}$ he then takes the cord of the pullies and draws on it gently, and as soon as a little tension begins he slips in between the ends of each girth, and close to the patient, a strut of wood one inch thick, from ten to eighteen inches long (according to her size), and four inches broad; in each end is a hollow notch three inches wide-i.e., long enough to secure the girth. These struts, by keeping the girths well asunder, prevent constriction of either abdomen or thorax, and in the latter case they obviate narrowing of the angles of the rib, which would otherwise result. With these struts and pads in position, the surgeon may now pull strongly on the cord. Of course he will not use as much force for a slim, delicate figure as he would for a shorter and sturdier one; he must also be guided by the amount of curvature, and the pull should not be continued leyond the first sensation of fatigue. I propose to call this process, since it loosens the shortened ligaments of the spine and muscles, "rachilysis." No pain whaterer accompanies or follows it; indeed, in several of my cases that weary pain in the back which so often accompanies curvature has been greatly relieved, so that girls have begged to be submitted to it more frequently than I had proposed.

Unfortunately the limited space at my disposal will not allow me to give cases, which shortly will be published elsewhere; but, instead, I will again-referring to Fig. 2point out very briefly how rachilysis affects the double curve (dorsal to right, lumbar to left). The loin girth upholds the convexity of that part, and the patient bending over to the left partly strengthens it. The dorsal curve, it must be remembered, reaches its acme about the fifth or six th vertebra, and from that point upward the spine slopes to the left. Now the padded loop encircling the patient's shoulder, but really acting on the upper part of the left thorax, counteracts this slope; while the dorsal girth placed at the culmination of the curve powerfully draws this righthanded bend to the left and may straighten it, even for a time convert it into a left bend, as in the patient from whom my figure was sketched; while the resistance against the force of the pulleys offered by the loin girth, still further bending the patient to the left, thus completely rectifies or even reverses the lumbar curve. Also, the patient being placed at the angle above deseribed between the ring in the floor and the hooks, rotation is greatly or entirely counteracted. Having thus set the spine free from its imprisoning bonds, it becomes after a certain number of repetitions amenable to treatment; nor have I, among a large number thus treated, been able to trace injury or even discomfort in a single case.

Wimpole-street, W.

\section{ON THE AN ESTHESIA PRODUCED BY THE ADMINISTRATION OF MIXTURES OF NITROUS OXIDE AND OXYGEN.}

By FREDERIC HEWITT, M.A., M.D. Cantab., INSTRUCTOR IN, AND LECTURER ON, ANESTHETICS AT THE LONDON HOSPITAL, ETC.

[Preliminary Notroe.]

EVERY anæsthetic with which we are acquainted possesses its special advantages and disadvantages, and nitrous oxide is no exception to this rule. The main objections to the gas as an anresthetic will be found to be almost wholly dependent upon the unfortunate property which it possesses of being irrespirable save for a brief space of time. I am, of course, taking it for granted that the gas is administered in its pure state and unmixed with air. After a short though variable period of inhalation, certain phenomena

4 In the figure, pads which guard the bandage from galling the patient are omitted for the sake of simplicity, nor is the turn of the body quite correctly given. 
occur to which I would direct special notice-phenomena which necessitate the withdrawal of the anesthetic and the admission of air to the lungs. Amongst these phenomena may be mentioned-lividity or actual cyanosis (varying with the previous colour of the patient's face), true stertor, jerky andirregular respiration, clonic movements in the extrenities and elsewhere, dilatation of the pupils, and considerable acceleration of the pulse-rate. Most, if not all, of these symptoms occur whenever the gas is administered to full surgical anresthesia, and they are, I believe, asphyxial in their origin -i. e., dependent upon the deprivation of oxygen, which necessarily accompanies the adninistration of the gas. In support of this view many clinical facts exist. In the first place, it is possible to secure ancsthesia (although such anesthesia is of an imperfect type), and to avoid all asphyxial complications, by the administration of nitrous oxide with a moderate quantity of air. In the second place, the phenomena above described will be found to be most pronounced in those cases in which, from any cause, the exit of nitrous oxide or the entry of atmospheric air is retarded at the close of the administration. Thirdly, although anrsthesia is most profound when the asphyxial symptoms are at their height, there always persists a period of available anisthesia after the symptoms in question have subsided by reason of the admission of air to the lungs when the face-piece has been removed. Lastly, as the late Paul Bert has shown, it is possible, by administering the gas with oxygen in a closed chamber in which the atmospheric pressure can be raised, to secure the full anæsthetic effects of nitrous oxide and the absence of all asphyxial complications. Nitrous oxide is, in fact, a true anæsthetic; and, were it not for the incidental manifestation of the phenomena to which I have alluded, would be capable of a much wider application than that which it at present enjoys. The concurrence of the asphyxial with the anæsthetic state led many persons in the earlier days of anæestheties to attribute the latter condition to the former; and even at the present day there are many who cannot be made to recognise that the symptoms due to the deprivation of air are only incidental to the administration. Nitrous oxide is only respirable to a certain limit, because during the administration the patient rapidly loses what oxygen he had in his air-passages and blood, and because he cannot obtain any from the gas which he is breathing. Moreover, the phenomena which arise towards the close of the administration occur very quickly, because the gas is rapidly and freely absorbed and the oxycen tension in the blood speedily lowered. The anæesthesia which remains after a full physiological dose of the gas is short (average twenty-five to thirty seconds) in consequence of the rapid escape of the nitrous oxide when air is admitted to the air-passages. We have, in fact, in nitrous oxide an agent which quickly produces anæsthesia with certain incidental symptoms due to the want of oxygen; and it is the manifestation of these incidental symptoms which constitutes the chief objection to the gas. It is true that experience has taught us that the phenomena mentioned are practically unattended by any risk to the patient; yet they have their objectionable aspect, not only from the point of view of the administrator, but also from that of the operator, to whom the jactitation is often highly inconvenient. I need not here enter in to the many other reasons why it would be preferable for the phenomena under consicleration to be conspicuous by their absence. It will be quite obvions to everyone that, if we could obtain by nitrous oxide an ansisthesia devoil of such phenomena, we should achieve an important step in the administration of anæsthetics. I am fully aware that some administrators do not push nitrous oxide so far as I have indicated; but all those who have worked for many years with the agent will agree that it is impossible to obtain full surgical anæsthesia without the manifestation of some of the symptoms referred to. If the administration be discontinued before such symptoms occur, the anæs thesia is very likely to be imperfect and consciousness insufficiently destroyed. I am willing to admit that in some instances total abolition of consciousness, freedom from pain, and quietude may be secured by a comparatively small dose of the gas; but such cases are very exceptional, and cannot be depended upon. Some have attempted to secure full anæsthesia with nitrous oxide by the occasional admission of a breath of air during the administration (in order to prevent the asphyxial phenomena); but the anæsthesia so produced is almost certain to be imperfect and unsatisfactory. We cannot help, in fact, inducing some of the objectionable symptoms if we wish to secure full anæsthesia by pure nitrous oxide as it is at present administered.

The late Paul Bert was, I believe, the first to attempt to produce a nitrous oxide anresthesia without any asphyxial manifestations. He made experiments upon llie lower animals with mixtures of nitrous oxide and oxygen, and appears to have come to the conclusion that these gases would not, if given together at ordinary atmospheric pressure, produce a satisfactory form of anxesthesia. He found that although he could abolish asphyxial complications by the mixture, the anxsthesia was incompl ste, and was attencled by such excitement as to render uperations impracticable. ${ }^{1}$ He pointed out that an increased atmospheric pressure was necessary for the administration of these gases in combination, and he argued as follows :"Le fait que le protoxyde d'azote doit être administré pur signifie que la tension de ce gaz doit, pour qu'il en pénètre une quantité suffisante dans l'organisne être égale à une atmosphère. Sous la pression normale, il faut, pour l'obtenir, que le gaz soit ì la proportion de 100 pour 100 . Mais, si nous supposons le malade placé dans un appareil où la pression soit poussée à 2 atmosphères, on pourra le soumettre à la tension voulue en lui faisant respirer un mélange de 50 pour 100 de protoxyde d'azote et 50 pour 100 d'air ; on devra donc obtenir de la sorte l'anésthesie, tout en maintenant dans le sang la quantité normale d'oxygène, et, par suite, en conservan t les conditions normales de la respiration."

There can be no doubt that Paul Bert's plan of giving the two gases together in a closed chamber in which the atmospherie pressure could be increased answered admirably, and had it not been for the cumbrous nature of the apparatus would have been very generally employed. The anæsthesia produced was perfect, and was free from all asphyxial phenomena. But the objection named was a formidable one; and although the method was actually put into practice, with the best results, it only enjoyed, by reason of the apparatus being so costly and cumbrous, a limited popularity. Subsequently attempts were made, more especially in Germany, to administer nitrons oxide with oxygen at ordinary atmospheric pressure. In 1886, Dr. Hillischer of Vienna ${ }^{2}$ reported many cases in which he had administered mixtures of the two gases for the purpose of producing anæsthesia during dental operations; but many of his cases were imperfectly anæesthetised, and several failer completely; moreover, the average available anxesthesia was not longer than that of ordinary nitrous oxide narcosis. Dr. Hillischer's example has, I believe, been followed to some extent in Germany; and Kreutzmann ${ }^{3}$ of San Francisco has also administered mixtures of the two gases.

Wishing to put to the test the practicability of producing satisfactory anæsthesia with nitrous oxide and oxygen, without employing a specially constructed chamber, I commenced in May, 1886, some experimental administrations at the Dental Hospital of London. Since then I have from time to time continued the investigation. I have given the gases by various methods and in various combinations; but I do not propose to describe in detail individual cases. In the first series of administrations I attached to the ordinary face-piece for the administration of nitrous oxide a small bag containing a mixture of 20 per cent. of oxygen with 80 per cent. of the gas: this bag was separated from the face-piece by a stopcock. Nitrous oxide was administered by the usual method till the ordinary signs of nitrous oxide narcosis commenced to appear, when the stopcock of the bag containing the mixture was opened. The latter procedure caused the abovementioned signs to subside; but when the face-piece was removed, the available anæsthesia was even shorter than if nitrous oxide alone had been employed, and the resultas were not satisfactory. In my second series I conducted the administration as described, but after the bag contraining the mixture had been placed at the disposal of the patient for a short time pure nitrous oxide was again administered. The cases in the second series were, however, similarly unsuccessful. In a third series of administrations $I$ interposed between the face-piece and the bag supplying the nitrous oxide a stopcock and dial in communication with a bag of pure oxygen. Nitrous oxide was first administered

1 Rottenstein: Traité d'Anesthésie Chirurgicale, p. 304. 2 Oesterreichisch-Ungarische Kerteljahrsschrift fiir '/ahnheilkurue, October, 1886, vol. ii., p. 343 . 
in its pure state; and as the administration proceeded the current of nitrous oxide was made to pass at the will of the administrator, and to any required extent, through the oxygen in the oxygen bag. None of these cases were, however, attended with satisfactory results. In a fourth series of cases $I$ tried the intermittent administration of nitrons oxide and a mixture of 20 per cent. of oxygen and 80 per cent. of the gas; but the results, on the whole, were unsatisfactory. In a fifth series of cases I employed a gasometer and variable percentages of oxygen. I found that a considerable percentage was necessary to prevent cyanosis and other symptoms, and I tried to find that percentage which would succeed in most cases. After a large number of experiments, I found (by an analysis very kindly made for me by Dr. Perey Frankland) that a mixture containing 1277 per cent. of oxygen answered admirably in eleven consecutive cases; and I was led to hope that this particular percentage would answer on all occasions. The anæsthesia which was produced quite astonished me. There was no excitement; the respiration was regularly and quietly performed; the colour of the cheeks and lips remained unimpaired or was even increased; there was no stertor; the available period of anesthesia was longer than that of nitrous oxide narcosis; and the recovery was perfect. I may here state that in these eleven cases I was absolutely certain as to the percentage of oxygen employed; for in seven out of eleven cases I was supplied by Messrs. Barth and Co. with known and correctly proportioned weights of nitrous oxide and oxygen in steel bottles, and in the other four cases the mixture used was analysed as I have mentioned. The hopes which I had entertained of being able to anesthetise all patients with this particular percentage were doomed to speedy disappointment, for in a sixth series of cases I worked with a percentage which was as near as possible identical with that previously employed so successfully, and of fourteen cases four failed, the patients becoming very excited, and one of them unmanageable. It seemed probable at this stage of the experiments that no definite percentage would succeed in every caso, but that different patients would require different percentages of oxygen. Messrs. Barth and Co. accordingly constructed for me an apparatus by which it was anticipated the percentage of oxygen could be accurately regulated during the administration. Next to the face-piece there was a mixing. cylinder, from which two tubes led to two rather large bags, one being fed by nitrous oxide, the other by oxygen. The mixing cylinder was furnished with a dial and indicator, and by the rotation of the latter it was presumed that any desirea percentage of oxygen could be added to the gas. I need not now enter upon the reasons why this apparatus failed.

From a careful consideration of the foregoing cases it was clear that those administrations which had been conducted by means of a gasometer and $12 \frac{3}{x}$ per cent. of oxygen were the most successful, although it must be admitted that several were not as satisfactory as could have been wished; and it seemed to me probable that the last-mentioned cases might have been brought to a successful issue if provision had been present forinereasing or diminishing the percentage of oxygen in response to the behaviour of the patient under the mixture. I therefore fitted up the apparatus figured in the annexed woodcut, which, it will be seen, was so arranged that, if more nitrous oxide or oxygen were required during the administration, the administrator could easily admit more. With this apparatus I anæsthetised in all seventy-eight patients. The figure shows clearly the plan which was adopted. The vertical measuring-rod of the gasometer was divided into eight equal parts. The gasometer was first charged with oneeighth of oxygen $(=121$ per cent. $)$, and seven-eighths of nitrous oxide were then added. The gasometer having been thus filled from the bottles upon the ground, the tap leading to the gas bag was turned and the latter partly filled. It will be observed that no counterpoise was used, so that the mixture issued under slight pressure. The administration was then commenced, expirations escaping through the valve of the stopcock. By the kind assistance of Mr. J. Percy Smith, house-surgeon at the Dental Hospital, and several students to whom I am also indebted, I was enabled to obtain full notes of the first fifty-nine of the seventy-eight cases. The average period of inhalation before the removal of the face-piece was 126 seconds; the verage available anasthesia after the removal of the facepiece was forty-four seconds; and the average quantity of the mixture required was eight gallons and three-quarters.
With one or two exceptions every patient was readily anæs thetised by the mixture I lave described; and in those instances in which excitement occurred, it either subsided spontaneously as the administration proceeded, or was controlled by freely supplying nitrous oxide to the gasometer when the mixture had been nearly exhausted. In one case only was there so much excitement as to necessitate the restraint of the patient's movements, and in this case the gasometer was found for some reason or another to have ceased working. 'The bearing of this fact will be subsequently appreciated.

In about 90 per cent. of the cases the following symptoms were produced by the administration of the mixture. Respiration was at first more or less accelerated, but the acceleration eventually became replaced, in many cases quite abruptly, by marked slowing of the breathing. No true stertor occurred ; indeed, the respiration, after about a minute, usually became as tranquil as that of ordinary sleep. The contrast between the jerky and trmultuous breathing of nitrous oxide narcosis, and the quiet, often almost imperceptible, respiration which characterised most of the cases, was very evident. With the exception of two cases in which I freely admitted nitrous oxide towards

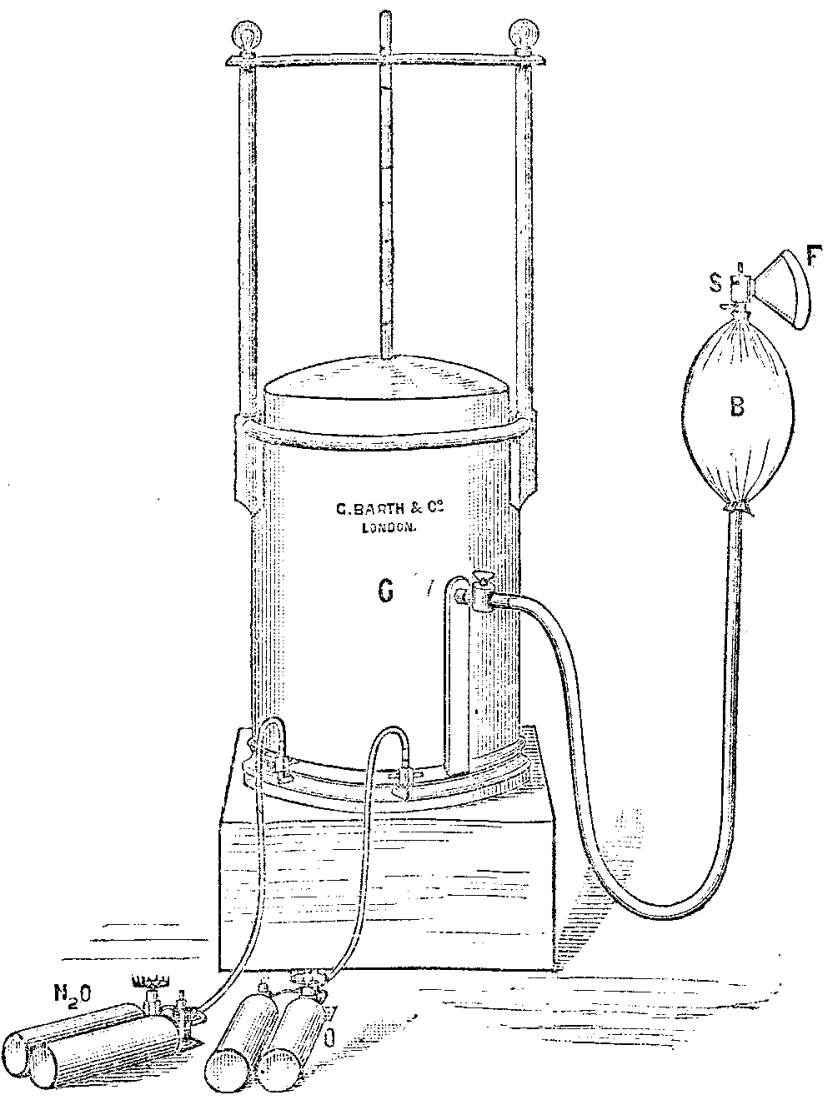

F, Face-piece. s, Stopeock with inspiratory and expiratory valves. B, Bag through which the mixture passes on its way to the face-piece. $N_{2} 0, A$ pair of bottles containing liquefied nitrous oxide. $\stackrel{O}{\circ}, A$ pair of bottles containing oxygen.

the close of the administration, there was not the slightest cyanosis in any instance; in fact, the colour of the patients' lips and cheeks was frequently brighter when the face-piece was removed than before its application. The pulse was usually full, strong, regular, and averaged about 80 or 90 to the minute. In many instances transient and slight rigidity of the extremities was noted, but subsided at or about the time that the respiration became slower. In one or two cases rigidity persisted throughout. In no case was there any clonic movement similar to that of ordinary nitrous oxide narcosis. It was often difficult to decide when to discontinue the administration and to allow the operator to commence; for nearly all the usual phenomena of full nitrous oxide anæsthesia were absent, and the mixture seemed as freely respirable as ordinary air. I found, however, that the eye gave valuable indications of anæsthesia. Any attempt to raise the upper lid during the earlier stages of the administration caused spasm of the orbicularis muscle; but when calm breathing and relaxation of the arms had occurred, the upper lid could usually be raised without inducing spasm, and so the eyeball could be observed. At this period the eyes were usually fixed and turned to the right or left; but in some 
instances they were directed forwards and then presented slight oscilatory movements. The usual conscious fixation of the eyes upon surrounding objects was absent. The pupils were variable, but never widely dilated. During the operations which were performed, the patients were, generally speaking, perfectly quiet; but in some instances a slight degree of reflex movement was observed. The recovery was, in the majority of cases, not quite so speedy as that from nitrous oxide, the patients of ten exhibiting a little temporary difficulty in maintaining their equilibrium, \&c. In one case vomiting occurred, but this was, I think, in consequence of blood which had been swallowed. No faintness was noticed or complained of in any case. The patients seemed to have less hesitation in breathing the mixture than in taking nitrous oxıde alone.

The results which I had obtained by using the gasometer and the mixture indicated were so satisfactory that I next attempted to devise a portable apparatus for conducting the administration upon the same principles. Messrs. Barth and $\mathrm{Co}$. therefore made for me two indiarubber bags having respectively the capacities of ten gallons and a half and one gallon and a half, and connected together by a wide metal trbe and stopcock. The large bag was fed from a pair of bottles containing nitrous oxide; the small one from a pair of bottles containing oxygen. From the large bag there passed a wide tube to the face-piece. The large bag was filled with nitrous oxide, and the small bag with oxygen; the stopcock between them was then opened, and their contents allowed to diffuse. Up to this time I had never fully appreciated the part played by pressure when using a gasometer. It soon became obvious, however, when comparing the results obtained by the use of the bags with those observed when employing a gasometer, that the pressure at which the mixture had been inhaled when using a gasometer was a most important element in the administration. I found, when administering the nixture from the bags described, that unless the bags were compressed during the inhalation the anxsthesia was liable to be imperfect and transitory; whereas, if by the aid of an assistant pressure was brought to bear upon the bags, the anresthesia was similar in its main features to that obtained by the use of the gasometer. I purposely conducted a few administrations without employing pressure, and waited until signs of excitement and imperfect narcosis commenced to appear; I then asked my assistant to compress the bags, and the result was that the symptoms mentioned subided and full anasthesia became established.

I have called this a preliminary notice because I am still continuing the investigation. I have ventured to publish the results which I lave up to the present time obtained, since I feel most strongly that attention should be directed to the remarkable anasthesia which characterised the majority of cases in which the mixture above described was adninistered under slight pressure from the gasometer. In looking through the accounts of gas-and-oxygen administrations conducted under what is termed ordinary atmospheric pressure, I have been unable to find any special reference to the necessity, soon after the commencement of the ardministration, of forcing the mixture, as it were, into the air-passages. Speaking generally, it will, I think, be clear, from the cases I have described, that attenipts to produce satisfactory ancesthesia with gas-andoxygen mixtures administered without provision for increasing the pressure in the air-passages will certainly fail. I cannot find that the late Paul Bert recognised the possibility of adninistering these gases under pressure, except by conducting the administration in a closed chamber, in which the barometrical pressure could be increased. If he or any other observer has recognised this possibility, I regret that $I$ am in ignorance of his results. The influence of the pressure which can be brought to bear by the over-distension of an indiarnbber bag, when the face-piece tits accurately, may not only be observed when using mixtures of nitrous oxille and oxygen, but also when employing nitrous oxide yer se. In the latter case it may be said that, other things being equal, the greater the pressure in the bay the more rapidly will anitsthesia ensue, and the more quickly will consciousness be subsequently establishel ; and rice verst. I have elsewhere brought forward eridence to show that the longer the patient can be made to inhale nitrous oxide, within certain limits, the longer will be the resulting anesthesia; and it seens to me that this fact niay be taken to explain the longer available anæsthesia which undonbtedly occurs when using nitrous oxide and oxygen. Even if a small quantity of atmospheric air be mixed with nitrous oxide, the usually bad effects of the dilution may be prevented by increasing the pressure at which the gas is given.

I am fully conscious of the imperfect character of this preliminary report; but I venture to hope that its shortcomings will be excused, seeing that it aims at nothing more than directing attention to an anæesthesia which may be produced by nitrous oxide and oxvgen without the costly and elaborate apparatus devised by the late Paul Bert. I am not at the present moment prepared to state that it is possible to secure this almost ideal form of anosthesia in every instance, even when using a gasometer and the mixture described. But in the majority of cases such an anæesthesia may be depended upon; and it is merely a matter of secondary importance to determine what means will be found to be best suited for bringing to a successful termination those exceptional cases in which symptoms of imperfect anæsthesia arise. I have not yet determined whether a simple increase of pressure will always suffice, or whether we should not have at hand the means for supplying pure nitrous oxide if required. These are, I think, minor considerations. The important fact remains - that a mixture of nitrous oxide with $12 \frac{3}{4}$ per cent. of oxygen, when administered under pressure from a gasometer, will in nearly every case produce a most satisfactory ancesthesia. I am now engaged in devising a portable apparatus for the administration of this mixture under pressure, and I hope soon to be able to publish the results. It will be obvious that the mixture I have indicated, when administered as described, may possibly be found to be available for operations of much onger duration than those for which it has hitherto been employed. But I hope to consider this as well as other important questions in a subsequent communication.

George-street, Hanover-square, w.

\section{Clinical a}

\section{MEDICAL, SURGICAL, OBSTETRICAL, AND THERAPEUTICAL.}

\section{CASE OF COUGH (REFLEX) AND CONVULSIONS DUE TO ADHERENT PREPUCE.}

By T. Grant Langhorne, M.R.C.S., L.R.C.P.Ed., \&e.

ON March 23rd, 1888, C. B-, a child aged five years, was brought to me by his mother with the following history. He had had a constant dry, hacking cough for the previous two years. It was always worse at night, and kept him awake for several hours, coming on in paroxysms, and often accompanied with convulsions. The mother had taken him to several medical men without any apparent benefit.

On examining the patient, I found him to be a wellnourisheu, healthy-looking child. There were no abnormal signs to be detected in his chest. His throat was slightly congested, but the tonsils were not enlarged. His pupils were widely dilated, which was no doubt due to some patent medicine he had been taking, for they became normal on ceasing to take it. I treated him for some time, with no relief to his symptoms, and was inclined to think his mother had exaggerated them, for I had never heard him cough, and he always appeared in perfect health when I saw him. However, on June lst I was sent for hurriedly about 2 A.M., the messenger saying that the child was choking, and that they thought he was dying. On reaching the house, I found the little patient gasping for breath, his face livid, and the pupils dilated, with general convulsions. Pulling down the bedclothes, I happened to notice his prepuce, which was unusually long and adherent; I could scarcely introduce a fine probe into the orifice. Believing that I had now found the cause of his symptoms, I gave him a whiff of chloroform and cireumcised him on the spot. By the time this slight operation was completed he was sleeping quietly, and since that time he has never had any return of his former symptoms.

I venture to think this case may prove of some in. 